\title{
Colombia: Teoría del ordenamiento
}

\section{Introducción}

La realidad se da en el universo objetivamente ordenada. Se ofrece al investigador como un sistema gobernado por la razón, accesible al conocimiento. Es lo que los griegos llamaron cosmos. Todo ordenamiento que emprendamos es, por eso, un reordenamiento.

Los indígenas de la Sierra Nevada dicen que Colombia está ordenada, que quienes estamos desordenados somos nosotros. Recomiendan que ordenemos el pensamiento para estar en capacidad de ordenar el país.

El propósito del ordenamiento está en armonizar territorio, población y gobierno. Se busca con ello garantizar el buen uso

\section{Alberto Mendoza Morales}

del territorio, la sostenibilidad del ambiente, el desarrollo de la población y un gobierno eficaz.

El ordenamiento, en el caso colombiano, buscará organizar la nación como un Estado Regional Unitario. Armonizará la variedad geográfica y ambiental del país, la heterogeneidad de la población y la red de unidades político-administrativas que gobiernan la nación. El reordenamiento ofrecerá una alternativa histórica entre el Estado Federal que ya probamos con escasa fortuna y el Estado Centralista vigente que nos tiene ahogados.

"Nada hay más práctico que una buena teoría". Eso dicen algunos pensadores. Ensayemos una teoría del ordenamiento. Examinemos un conjunto de enunciados

$\overline{\text { * Arquitecto, }}$ Presidente Sociedad Geográfica de Colombia. 
y pensamientos que nos predispongan, con razonables argumentos, a cumplir la tarea práctica de remodelación institucional que Colombia reclama y necesita.

\section{Definiciones}

Toda definición restringe. Definir, sin embargo, es la única manera de saber de qué estamos hablando y cómo entendernos.

El ordenamiento de un país es la distribución espacial de las configuraciones que sustenta, geográficas, ecosistémicas, humanas y políticoadministrativas. El ordenamiento es, por tanto, una cuestión holística, es decir integral. Su aplicación discurre a lo largo de tres ejes: territorial, étnico-cultural y político-administrativo.

\section{Ordenamiento territorial}

El ordenamiento territorial, como su nombre lo indica, es geográfico. Comprende entidades territoriales y ecosistemas. Incluye usos del suelo, urbanos y rurales, existentes y propuestos.

Entidades geográficas son las regiones, configuraciones terrestres naturales, discernibles por poseer alguna característica físico-ambiental que las identifica y define, selva, mar, río, llanura, lago, montaña, etc. Vistas en un mapa dan la imagen de un mosaico territorial.

Las regiones tienen ser propio, existen por sí mismas, las aporta la naturaleza, se delimitan según linderos arcifinios, no se decretan, se reconocen, las ordena y modifica la naturaleza misma, el hombre las habita, las utiliza, las modifica, las equipa y las tiene como escenario de su relación con la tierra y su devenir histórico. El hombre no construye regiones, las modifica y equipa para su uso, más bien las destruye.

Las regiones son de tres clases, macroregiones representadas por los continentes de la Tierra y los océanos y mares que los rodean. Meso-regiones, representadas por los espacios que conforman los continentes. Regiones propiamente dichas, áreas que componen los Espacios Continentales. Las cuencas hidrográficas, de todas dimensiones, entran como espacios continentales, regiones o partes de ellos.

Los Espacios Continentales, por su extensión, suelen pertenecer a uno, dos o más países; aportan base geopolítica para sus relaciones, tratados y manejo fronterizo. Los espacios continentales de Sudamérica son once, de ellos seis entran a formar el mosaico geográfico de Colombia: Amazonia, Orinoquia, Espacio Marabino, Espacio Andino, Espacio Caribe y Espacio Pacífico. Todos, continentales y nacionales, tienen vocación legitima para ser organizados como Regiones Administrativas y de Planeación, RAP.

Cada espacio continental o región formulará su respectivo Plan de Ordenamiento mediante la concurrencia 
deliberada de las entidades politicoadministrativas que tienen asiento en el respectivo espacio. La integración orgánica de los seis planes macroregionales constituirá el Plan Nacional de Ordenamiento Territorial.

Las regiones propiamente dichas son aquellos territorios discernibles dentro de los espacios continentales. Los caracterizan sus condiciones físico-ambientales individuales que las diferencias entre sí. Son regiones propiamente dichas, por ejemplo, La Guajira, el valle del río Sinú, La Sierra Nevada de Santa Marta, la Depresión Momposina, el Alto Magdalena, el Magdalena Medio, el Macizo Colombiano, para citar solamente algunos ejemplos. Las regiones propiamente dichas serán graficadas en los mapas correspondientes a cada Espacio Continental y sus respectivos planes se formularán en concordancia con ellos.

Cuencas hidrográficas son concavidades terrestres por donde corren un río principal y sus afluentes. Además de fluviales, las cuencas hidrográficas son también oceánicas, marítimas y lagunares, según las comanden un océano, un mar o un lago. Las cuencas hidrográficas, sustentadoras del agua, serán objeto de ordenamiento territorial específico y tratamiento especial según su condición y tamaño.

El ordenamiento ambiental se refiere a la parte del ordenamiento territorial correspondiente al conjunto de circunstancias, condiciones, cosas e influencias, vivientes o inanimadas, que se dan en un determinado territorio. El ordenamiento ambiental se expresa en los paisajes que presenta el territorio y los ecosistemas que contienen. El inventario del patrimonio ambiental se graficará en cartas geográficas.

\section{Ordenamiento étnico-cultural}

El ordenamiento étnico-cultural hace relación a la población del país. Trata la localización de los grupos humanos distinguibles en el territorio por raza, procedencia, condición y tradición, por sus características culturales, sociales y económicas y por sus asentamientos en el territorio.

\section{Ordenamiento político-administrativo}

El ordenamiento político-administrativo se refiere a las unidades de manejo del estado en todos sus niveles, nacional, intermedio y local. Trata su organización, jerarquización, condiciones de creación y eliminación, funciones, competencias y atribuciones, regulación técnica, territorial, política y jurídica y manera de resolver conflictos de competencias.

Colombia se organizará con base en tres unidades político-administrativas, correspondientes a tres niveles de gobierno: el estado, los departamentos y los municipios. La regionalización del estado vendrá por evolución producto de una fase superior de su organización. Las restantes unidades -provincias, distritos, áreas metropolitanas y otras- tendrán el carácter de unidades de apoyo y coordinación. 
El estado es un pueblo políticamente organizado, asentado sobre un determinado territorio, con gobierno y normas propias de funcionamiento; es, por encima de todo, una expresión de poder que califica de soberano pues no admite ninguno otro por encima de sí. El pueblo es la nación. El territorio es el país; la organización es política, la recoge la Constitución Nacional. El estado es una forma de elevada convivencia. Su razón de ser es la seguridad de los asociados y su progreso. Se supone que promueve las libertades públicas, el desarrollo y el ascenso cultural de la población. El Estado Regional Unitario retiene las funciones centrales: dirigir la economía, las relaciones exteriores, la planificación, la administración del conjunto, la justicia, la educación, la salud, las fuerzas armadas. La administración del estado se da en tres ramas independientes pero armónicas: legislativa, ejecutiva, judicial. Se requiere establecer la rama de control que represente el poder ético.

La financiación del estado se hará con los aportes de la población por todo concepto, impuestos, tasas, contribuciones, regalías y otros. Formarán un solo monto. La suma consolidada se distribuirá, $30 \%$ para funcionamiento del gobierno central y $70 \%$ para funcionamiento de departamentos y municipios.

Los departamentos son unidades político-administrativas, dotadas de territorio, en que se divide el país. Son unidades intermediarias entre los municipios y el gobierno nacional. Están dotados de autonomía para determinar la estructura de su administración, las funciones de sus dependencias y las escalas de remuneración de sus servidores. Sus funciones: orientar, coordinar y complementar acciones municipales; planificar el desarrollo departamental y del ordenamiento territorial; proyectar y conducir obras públicas; preservar el medio y el ambiente. Los departamentos se pueden asociar y organizar como Regiones de Administración y Planeación RAP, asentadas sobre las regiones geográficas.

El municipio es la entidad fundamental del estado. Los municipios significan la cercanía del gobierno a los ciudadanos. Existirá municipio allí donde la gente se establezca en un territorio, se organice, designe autoridades, se dedique a resolver los problemas de la comunidad y tenga capacidad de autosostenerse. Tienen autonomía para determinar su estructura $\mathrm{y}$ las funciones de sus dependencias. $\mathrm{Su}$ tamaño y funcionamiento se dispondrá de acuerdo con sus propias circunstancias de lugar, población y capacidades, de las cuales dependerá su estructura administrativa y las funciones de sus dependencias. Tendrán a su cargo el manejo de todo cuanto sea próximo y esencial al hombre: organización de la comunidad, cultura, vivienda, educación, salud, deportes, servicios públicos, policía, medio ambiente, conservación de los recursos naturales, ordenamiento territorial, fomento agrario, control de usos de la tierra y planeación del desarrollo local. La policía será municipal. Los municipios se dividirán en veredas y corregimientos. 
Veredas. El país se reorganizará desde las veredas y por acción comunal. Se organizarán como centros de vida y trabajo dotadas de los servicios que demande la óptima calidad de vida de la población veredal. Cada vereda contará con una Junta de Acción Comunal articulada con las Unidades Municipales de Asesoría Técnica Agraria. UMATAS. Las veredas se asociarán en corregimientos. Estos dispondrán, cuando menos, de puesto de salud y puesto de policía.

Los territorios indígenas y afrocolombianos se organizarán como municipios teniendo en cuenta lo que es específico y propio de sus habitantes, su etnia, su cultura, sus tradiciones.

Los Distritos son unidades administrativas de régimen especial que se conformarán y decretarán para el manejo de territorios que, por su naturaleza, requieren atención especializada por ejemplo los hitos notables del país: Sierra Nevada de Santa Marta, isla de Calamarí, isla de Mompós, Depresión Momposina, Sierra Nevada del Cocuy, Parque de los Nevados, Páramo de Sumapaz, Nevado del Huila, Macizo Colombiano.

Las provincias son unidades territoriales conformadas por la asociación de municipios de un mismo departamento; estarán destinadas a profundizar la identidad de la población, a coordinar actividades de las unidades asociadas y a impulsar proyectos de interés subrregional.

Area metropolitana es el conjunto formado por una metrópolis y las ciudades y poblaciones que la acompañan en proximidad. Les corresponderá formular y adoptar su respectivo plan de ordenamiento territorial y definir objetivos, criterios y normas, en igualdad de condiciones, que deben acoger y aprobar los municipios involucrados en el área.

\section{Ley Orgánica de Ordena- miento}

La Ley Orgánica de Ordenamiento es una cúpula política que cubre y encierra un modelo de arquitectura jurídica. Tiene por objeto establecer los principios rectores del ordenamiento del estado y dictar las normas que lo regirán. Por ser integral, incluirá la Ley Orgánica comprenderá los tres ejes del ordenamiento, territorial, étnico-cultural y político-administrativo. Por naturaleza requiere aprobación por mayoría absoluta de votos. Para su aplicación, la Ley Orgánica de Ordenamiento, igual que la Constitución Nacional, será desagregada en leyes particulares. 
